\title{
Corticotherapy for traumatic brain-injured Patients - The Corti-TC trial: study protocol for a randomized controlled trial
}

\author{
Karim Asehnoune ${ }^{1,4^{*}}$, Antoine Roquilly, ${ }^{2,4}$, Véronique Sebille ${ }^{3,4}$ and The Corti-TC trial group $p^{2,4^{*}}$
}

\begin{abstract}
Background: Traumatic brain injury (TBI) is a main cause of severe prolonged disability of young patients. Hospital acquired pneumonia (HAP) add to the morbidity and mortality of traumatic brain-injured patients. In one study, hydrocortisone for treatment of traumatic-induced corticosteroid insufficiency $(\mathrm{Cl})$ in multiple injured patients has prevented HAP, particularly in the sub-group of patients with severe TBI. Fludrocortisone is recommended in severe brain-injured patients suffering from acute subarachnoid hemorrhage. Whether an association of hydrocortisone with fludrocortisone protects from HAP and improves neurological recovery is uncertain. The aim of the current study is to compare corticotherapy to placebo for TBI patients with $\mathrm{Cl}$.

Methods: The CORTI-TC (Corticotherapy in traumatic brain-injured patients) trial is a multicenter, randomized, placebo controlled, double-blind, two-arms study. Three hundred and seventy six patients hospitalized in Intensive Care Unit with a severe traumatic brain injury (Glasgow Coma Scale $\leq 8$ ) are randomized in the first 24 hours following trauma to hydrocortisone (200 mg.day ${ }^{-1}$ for 7 days, $100 \mathrm{mg}$ on days 8-9 and $50 \mathrm{mg}$ on day-10) with fludrocortisone $(50 \mathrm{\mu g}$ for 10 days) or double placebo. The treatment is stopped if patients have an appropriate adrenal response. The primary endpoint is HAP on day-28. The endpoint of the ancillary study is the neurological status on 6 and 12 months.
\end{abstract}

Discussion: The CORTI-TC trial is the first randomized controlled trial powered to investigate whether hydrocortisone with fludrocortisone in TBI patients with $\mathrm{Cl}$ prevent HAP and improve long term recovery.

Trial registration: NCT01093261

Keywords: Trauma, Traumatic brain injury, corticosteroid insufficiency, glucocorticoid, mineralocorticoid, pneumonia, nosocomial infection, intensive care unit

\section{Background}

Traumatic brain injury (TBI) is a leading cause of prolonged disability in young patients. The rate of hospital acquired pneumonia (HAP) varies from 30 to $50 \%$ [1-3]. Post traumatic HAP increases the risk of intracranial hypertension [4], prolongs duration of mechanical ventilation and Intensive Care Unit (ICU) length of stay $[5,6]$ and may increase the rate of death [7]. Prevention of one episode of HAP may save 20,000\$ [8].

\footnotetext{
* Correspondence: karim.asehnoune@chu-nantes.fr; karim.asehnoune@chunantes.fr

${ }^{1}$ Centre Hospitalier Universitaire de Nantes, Service d'anesthésie réanimation chirurgicale, Hôtel Dieu-HME, Nantes, France

${ }^{2}$ Intensive care Unit, Hotel Dieu, (Place Ricordeau), Nantes (44093), France Full list of author information is available at the end of the article
}

Critical Illness Related Corticosteroid Insufficiency (CIRCI) reaches up to 50 to $70 \%$ of trauma patients [9-11]. CIRCI increases systemic inflammation and vasopressive requirement $[9,12]$. Hydrocortisone decreases rate of HAP and duration of mechanical ventilation in multiple trauma patients with CIRCI [10]. In a subgroup analysis of the HYPOLYTE trial, hydrocortisone appears particularly efficient in multiple trauma patients with TBI [10]. Fludrocortisone was proposed in association with hydrocortisone for the treatment of CIRCI in septic patients [13] and is recommended in BI patients with spontaneous subarachnoid hemorrhage who experience hyponatremia [14]. No data regarding fludrocortisone use in TBI patients are available to date.

\section{C) Biomed Central}


The CORTI-TC study aims to test the effects of prolonged low dose of hydrocortisone together with fludrocortisone for prevention of HAP and long term neurological and psychological recovery in patients with severe TBI.

\section{Methods and Design}

\section{Objectives and design}

The Corticotherapy in traumatic brain-injured patients (CORTI-TC) study is a nationwide multicenter, randomized, double blind, placebo controlled trial. The Institutional Review Board of Tours (France) approved the study protocol. The CORTI-TC is conducted in accordance with the declaration of Helsinki and was registered on March 232010 at http://clinicaltrial.gov/ with trial registration NCT01093261.

\section{CONSORT diagram}

Figure 1 shows the CONSORT diagram of the CORTITC trial.

\section{Study population}

Investigators screen consecutive severe TBI patients defined as the association of a Coma Glasgow Scale $\leq 8$ together with a traumatic anomaly on tomodensitometry. Inclusions criteria are: severe traumatic BI, in the first 24 hours following trauma, age between 15 and 65 years and informed consent from a next-of-kin. Exclusions criteria are: associated tetraplegia, previous immunosuppression, corticotherapy in the previous 6 months, antibiotherapy for active sepsis at the time of inclusion.

\section{Randomization}

Patients eligible for inclusion should be randomized, and the study treatment is started within the first 24 hours. Patients are randomized in a 1:1 ratio in fixed blocks of 12 and stratified according to the center and MGAP score [15] by a computerized number generator list provided by a statistician not involved in the determination of eligibility or in the assessment of outcomes. All assignments are made through a dedicated, pass-word protected, SSL-encrypted website. Randomized patients are given a number corresponding to a "Corti-TC treatment pack» that contains: $20 \times 100 \mathrm{mg}$ vial of hydrocortisone or placebo, 10 pills of $50 \mu \mathrm{g}$ of fludrocortisone or placebo and a sheet for schedule administration.

\section{Study protocol}

Immediately after randomization, and before study drug administration, a short corticotropin test is performed (basal cortisolemia followed by $0.25 \mathrm{mg}$ of synacthene ${ }^{\circledR}$ and cortisolemia on the $60^{\text {th }} \mathrm{min}$.). Patients are randomized to intravenous infusion of hydrocortisone (200 mg. day $^{-1}$ for 7 days, $100 \mathrm{mg}$ on days -8 and $-9,50 \mathrm{mg}$ on day10) with enteral administration of fludrocortisone $(50 \mu \mathrm{g}$. day $^{-1}$ for ten days) or to placebo. After receiving the results of the short corticotropin test (usually in the first 48 hours following inclusion), the treatment is stopped if patients have an adapted corticosteroid function.

\section{Protocol drop-out}

Clinicians are allowed to use corticotherapy at any time point if there is an absolute adrenal insufficiency (basal cortisolemia below $30 \mu \mathrm{g} . \mathrm{dl}^{-1}$ ), a septic shock or an Acute Respiratory Distress Syndrome. Enteral administration of the study drug (Fludrocortisone or Placebo) can be stopped in case of hypernatremia $\left(>155 \mathrm{mmol.}^{-1}\right)$ associated with a low natriuresis $\left(<20 \mathrm{mmol}^{-1} \mathrm{l}^{-1}\right.$. The complete follow up is always performed and patients are kept in the statistical analysis.

\section{Biological assessment}

Immediately before starting the treatment, but at least 8 hours after a bolus injection of etomidate [10,13], a short corticotropin test is performed: cortisolemia before and 60 minutes after an intravenous bolus of $0.25 \mathrm{mg}$ of corticotropin (Novartis ${ }^{\circledR}$, Rueil-Malmaison, France). A second short corticotropin test is performed on day-11 or -12 . At the same time points, plasma and serum are frozen at $-80^{\circ} \mathrm{C}$ for ancillary studies.

\section{Study end points}

Primary endpoint is the occurrence of HAP within 28 days of randomization. Pneumonia is considered when at least 2 signs (body temperature $>38^{\circ} \mathrm{C}$; leukocytosis $>12000 / \mathrm{mL}$, or leukopenia $<4000 / \mathrm{mL}$; purulent pulmonary secretions) associated with the appearance of a new infiltrate are present or when changes occur in an existing infiltrate on chest $\mathrm{x}$-ray. The diagnosis needs to be confirmed by a respiratory tract sample using a quantitative culture with a predefined positive threshold of $10^{4}$ colony-forming units per milliliter $(\mathrm{CFU} / \mathrm{mL})$ for a bronchoalveolar lavage or non bronchoscopic sample, of $10^{3} \mathrm{CFU} / \mathrm{mL}$ for a protected specimen brush and of $10^{6} \mathrm{CFU} / \mathrm{mL}$ for a tracheal sample. Hospital-acquired pneumonia is defined as pneumonia that occurs 48 hours after admission that had not been incubating at the time of admission.

The secondary outcomes are duration of mechanical ventilation and length of ICU stay, antibiotic free days, rate of death, other infections, organ failures, and duration of vasopressor support on day 28 and in ICU. Safety is assessed by recording adverse events.

An ancillary study will assess the mortality, the long term neurological and psychological recovery on the $-6^{\text {th }}$ and $-12^{\text {th }}$ month. 


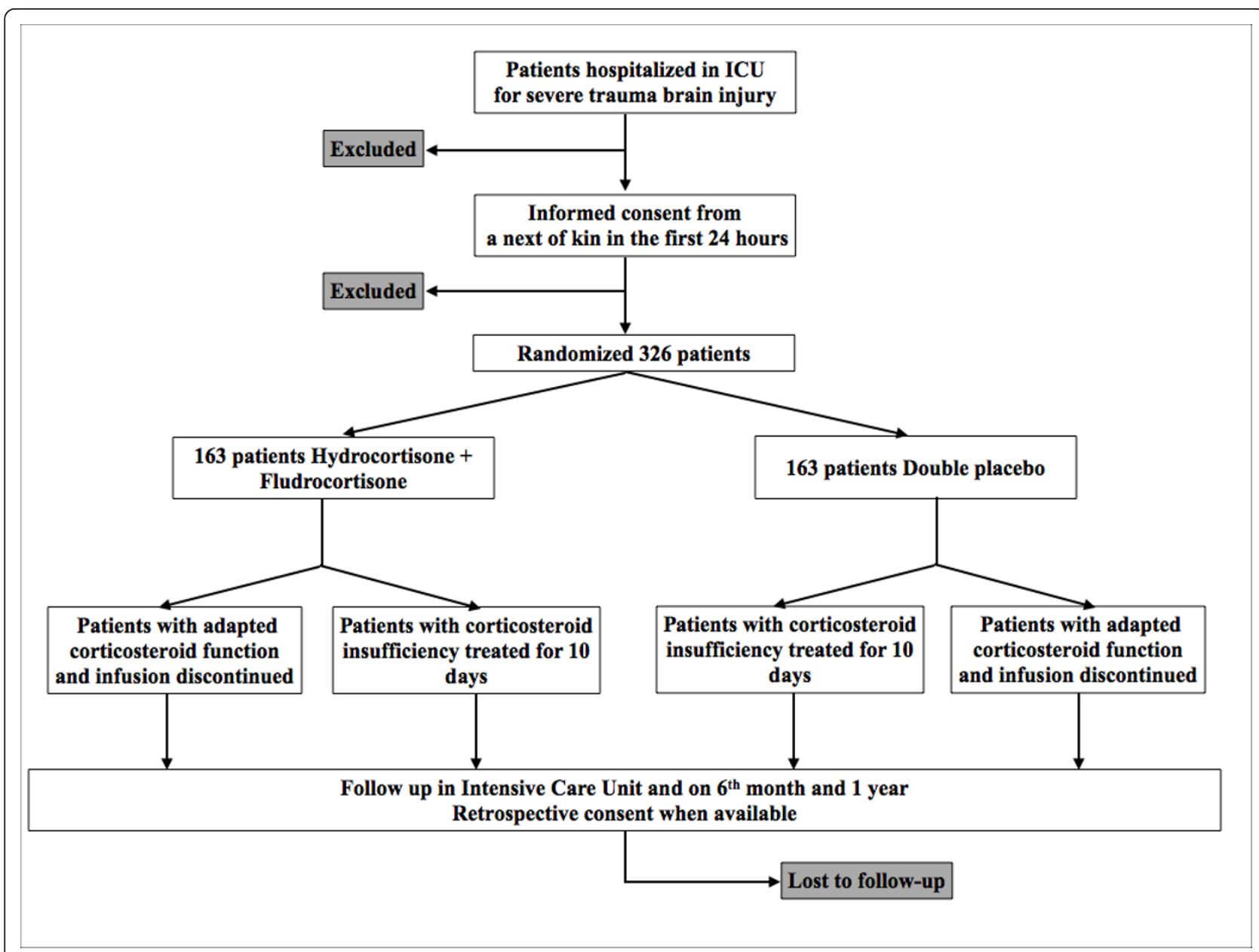

ICU: Intensive Care Units

Figure 1 CONSORT diagram of the CORTI-TC trial

\section{Follow up}

The following variables are collected: demographics, Apache 2, MGAP score [15], injury severity score and abbreviated injury score, fluid infusions, vasopressors, antibiotherapy, etomidate use, surgery, intracranial pressure, infections, organ failures, natremia, length of ventilatory support, and ICU hospitalisation and death in ICU and at day 28 are recorded. In ICU, clinical assessments are performed at least twice a day. Clinical evaluation for diagnosis of pneumonia are performed twice a day in the ICU. A chest x-ray is performed as soon as pneumonia is suspected after clinical examination. A respiratory tract sample is collected for bacteriological analysis before any modification of antibiotic therapy. Patients or relatives are contacted on -6 and -12 month for evaluation of neurological recovery (GOS, Kartz index), of quality of life, of depression disorder (HAD scale, SF-36 and I.E S-R scores) and of mortality.

\section{Statistical consideration}

The required sample size is calculated from results of the HYPOLYTE study [10]. The power calculation is performed for comparison between the hydrocortisone and placebo groups in patients with corticosteroid insufficiency. The sample size needed to detect an absolute decrease in pneumonia incidence of $20 \%$ is 121 patients in each group, assuming a rate of $70 \%$ in the placebo group, in a 2 -sided test performed with a statistical power of $90 \%$ and an $\alpha$ risk of $5 \%$. Assuming a rate of $75 \%$ of corticosteroid insufficiency [10], 326 patients 
(approximately 163 patients in each group, and 41 patients with normal corticosteroid function who are untreated) are needed. Two a priori interim analyses using the O'Brien and Fleming method for $\alpha$ risk spending are planned respectively after the inclusion of 110 and 220 patients.

An ITT and a mITT analysis will be performed. Because the patients with adapted corticosteroid function are left untreated (when the cosyntropin test show no corticosteroid insufficiency), a modified intention-totreat (mITT) analysis that includes only the patients with corticosteroid insufficiency is planned.

\section{Statistical analysis}

Primary outcome is the occurrence of HAP within the first 28 days after randomization. The primary analysis will use a Cox multivariate proportional hazards model that includes 2 predefined covariable: MGAP [15] and Coma Glasgow Score. We will also perform complementary sensitivity analyses with an adjustement on etomidate use. Corresponding hazard ratios (HRs) along with their 95\% confidence intervals (CIs) will be reported. The crude percentages and the Kaplan-Meier estimators will also be presented. Cumulative incidence will also be estimated for the primary outcome by treating deaths as competing risks. The Fine and Gray model [16] will be used. If a difference is confirmed for the primary endpoint, subgroup analysis for multiple trauma (presence or absence), hyporeactivity to adrenocorticotrophic hormone (presence or absence), early treatment administration ( $<18$ hours after trauma or $>18$ hours) will be performed. In order to control the family wise error rate, a stepwise hierarchal testing procedure will be used for subgroup analyses.

Normally distributed variables will be expressed as mean and standard deviation; non-normally distributed variables will be expressed as median and inter quartile ranges. Categorical variables will be expressed as numbers and percentage, as well as the absolute difference (95\% CI). Linear or logistic regressions will be used as appropriate for the secondary endpoints.

\section{Study Organization}

The financial support are provided by the Société Française d'Anesthésie Réanimation (SFAR). Study promotion is performed by Nantes University Hospital.

The independent Data and Safety Monitoring Board (DSMB) look over the ethics in accordance with the Declaration of Helsinki, monitors patient safety and reviews safety issues as the study progresses. Serious adverses events and unexpected related or possibly related serious events are reported blinded to the DSMB within respectively 24 hours or 7 days.
Patients are treated in level I trauma centers according to the Advanced Trauma Life Support principles.

\section{Discussion}

The Corti-TC trial is the second randomized controlled study powered to investigate prolonged low dose of corticosteroid therapy in severe trauma patients, and the first one focusing on severe TBI patients.

Cortisol production is necessary for normal host defence against infection. Hydrocortisone dampens inflammation while preserving innate immunity [17] and improves the recovery from severe community-acquired pneumonia [18]. Trauma-induced inflammation, which is exacerbated in cases of corticosteroid insufficiency [19], leads to infection [12]. In the HYPOLYTE study [10], low dose of hydrocortisone decreased rate of HAP in intubated trauma patients with corticosteroid insufficiency.

The primary outcome of this trial is HAP, that could be considered as a shortcoming since the prevention of HAP does not always improves outcomes of ICU patients [20]. Infections are the most frequent cause of complications in severely injured patients [21]. The incidence of pneumonia is particularly high in trauma patients, reaching up to 50\% [2-4]. Post-trauma pneumonia is responsible for an increased morbidity (duration of mechanical ventilation and ICU hospitalization) $[5,6]$, and the average cost for each pneumonia episode is high [8]. In the HYPOLYTE study, together with a decreased in rate of HAP, hydrocortisone decreased both duration of mechanical ventilation and ICU length of stay. Thus, we considered that the most relevant endpoint would be HAP.

Criteria for HAP diagnosis has not been studied in trauma patients treated with hydrocortisone and theoretically the study treatment may decrease the ability of clinician's to diagnose HAP. For community-acquired pneumonia, the body temperature of patients treated with a high dose of glucocorticoid was slightly decreased (by less than $0.5^{\circ} \mathrm{C}$ ) as compared to placebo-treated patients [22], but to our knowledge, the effects of stress dose hydrocortisone (if any) are unknown in trauma patients. Also, in case of CIRCI hydrocortisone should restore the ability to develop fever, and patients without CIRCI (left untreated) should not present any dysregulation in thermoregulation abilities. Finally, we assumed that hydrocortisone with fludrocortisone will not biased HAP diagnosis.

Major modifiable risk factors for HAP as described by the American thoracic Society [23] are prospectively collected: oropharyngeal decontamination, proclive $\left(>30^{\circ}\right)$, stomach ulcer prevention, insulinotherapy, tracheostomy and protocol for sedation. All these factors can not be standardized in the protocol. Sedation is a cornerstone 
therapy for intracranial hypertension [24]. Therefore, it was not practical to perform either daily spontaneous breathing trials or daily liberation from sedation in a population of traumatic brain injury patients. Concerning tracheostomy, prevention of HAP by performing tracheostomy early is still debated. In a recent study, the incidence of HAP was similar in patients with early versus late tracheostomy [25]. None of the participating ICUs usually perform early tracheostomy or "daily spontaneous breathing" in TBI patients during the study period. Regarding insulinotherapy, tight glycemia control is a highly debated topic for ICU patients and is associated either with beneficial [26] or deleterious effects [27]. A tight glycemic control was not associated with any survival improvement of septic patients treated with hydrocortisone [28]. Proclive and oropharyngeal decontamination are commonly used in participating ICUs. Finally, a controlled double-blind randomized design may ensure the comparability of groups for the majority of interventions other than hydrocortisone infusion.

In this study, we use a placebo in a population of CIRCI patients. This point do not raise an ethical issue as the recommendations for the diagnosis and treatment of CIRCI recently published by the American College of Critical Care Medicine [29] state that: first, given the lack of data, treatment of CIRCI is not recommended in other population than septic shock patients; second, a call for studies in ICU populations other than septic patients (including trauma patients) was advocated. Moreover, a placebo is ethically justified because the placebo is given in addition to standard of care of TBI patients.

The selection of ICU patients who require hydrocortisone treatment is of particular importance. The concept of CIRCI has recently been introduced to differentiate the classical chronic corticosteroid insufficiency (Addison's disease) from the alteration of the hypothalamic-pituitary-adrenal axis observed in ICU patients [29]. CIRCI corresponds to an inadequacy between the severity of illness and the corticosteroid activity [19]. The combination of basal cortisolemia and/or a delta $<9 \mu \mathrm{g} / \mathrm{dl}$ provides the best specificity and sensitivity for the diagnosis of CIRCI associated with severe sepsis [30]. Finally, recent recommendations have advocated use of either the basal cortisolemia or delta for diagnosis of CIRCI [31]. Regarding threshold of the basal cortisolemia, our definition is more liberal $(<15 \mu \mathrm{g} / \mathrm{dl})$ than the consensus statement $(<10 \mu \mathrm{g} / \mathrm{dl})$. In the HYPOLYTE study using this liberal definition [10], patients with a normal corticosteroid function have a trend toward a decrease in rate of HAP as compared to patients with corticosteroid insufficiency treated with placebo $(P=.06)$. Finally, the
Corti-TC trial is not designed to test the accuracy of the CIRCI definition in trauma patients.

Despite inhibition of the cortisol synthesis, etomidate is recommended for Rapid Sequence Induction of multiple trauma patients [31]. For single bolus injection, the duration of adrenal blockade varies from 12 hours [32] to 24 hours [33], but it should be noted that this blockade was inconstantly reported [34]. In the Corti-TC study, a corticotropin test will not be performed within the first 8 hours following etomidate infusion and etomidate use in ICU is discouraged. Finally, as etomidate use may impact the results, etomidate will be considered as an effect modifier for the analysis (sensitivity analysis).

In conclusion, the Corti-TC trial is a nationwide investigator-initiated randomized controlled trial powered to test the hypothesis that the association of hydrocortisone with fludrocortisone in severe TBI patients prevents HAP. The Corti-TC trial also determines the effects of low dose of corticosteroids on duration of mechanical ventilation, length of ICU stay, organ failures and rate of death. An ancillary study will assess the long term neurological and psychological recovery of the included patients.

\section{Trial status}

On October, the 5 th of 2011, 110 patients have been enrolled in the study. The first interim analysis will be performed in november 2011, after the collection of the primary end point of the 110 th patient.

\section{List of abbreviations}

BI: Brain Injury; CIRCI: Critical IIIness Related Corticosteroid Insufficiency; CFU: Colony Forming Unit; DSMB: Data and Safety Monitoring Board; HAP:

Hospital Acquired Pneumonia; ICU: Intensive Care Unit; ITT: Intention-to-treat.

\section{Acknowledgements}

This study is an investigator-initiated trial, funded by the Société Française d'Anesthésie Réanimation (SFAR)

And for the corti-TC trial group*:

Alphabetical order of centers:

Intensive care Unit, University Hospital, (Place Pauchet), Amiens, (80080),

France:

Hervé DUPONT: Dupont.Herve@chu-amiens.fr

Patrick JEANJEAN jeanjean.patrick@chu-amiens.fr.

Intensive care Unit, University Hospital, (Rue Larrey), Angers (49100), France: Soizic GERGAUD: SoGergaud@chu-angers.fr,

Sigismond LASOCKI: sigismond@lasocki.com.

Intensive care Unit, University Hospital, Beaujon-Clichy AP-HP, (Bvd Leclerc),

Clichy (92118), France:

Jérémy ALLARY: jeremy.allary@bjn.aphp.fr

Tobias GAUSS: tobias.gauss@bjn.aphp.fr

Jean MANTZ: jean.mantz@bjn.aphp.fr.

Intensive care Unit, University Hospital, (Place Rabat-Leon), Bordeaux, (33000),

France:

Matthieu BIAIS: matthieu.biais@chu-bordeaux.fr

Vincent COTTENCEAU: vincent.cottenceau@chu-bordeaux.fr

François DELAUNAY: francois.delaunay@chu-bordeaux.fr

Françoise MASSON: francoise.masson@chu-bordeaux.fr

Philippe REVEL: philippe.revel@chu-bordeaux.fr 
François SZTARK: francois.sztark@chu-bordeaux.fr.

Intensive care Unit, University Hospital, (Rue Tanguy Prigent), Brest (29000)

France:

Jean-Philippe AUBOUIN: jean-philippe.aubouin@chu-brest.fr

Guy COCHARD: guy.cochard@chu-brest.fr

Anne DE TINTENIAC: anne.detinteniac@chu-brest.fr

Edith ETIENNE: edith.etienne@chu-brest.fr

Hervé FLOCH: herve.floch@chu-brest.fr

François LION: lionpost@hotmail.fr

Bénédicte NANCY: benedicte.nancy@chu-brest.fr

Philippe REYNAUD: philippe.reynaud@chu-brest.fr

Jean Paul WARGNIER: jean-paul.wargnier@chu-brest.fr.

Intensive care Unit, University Hospital, (Cote de Nacre), Caen (14000),

France:

Jean-Luc HANOUZ: hanouz-j|@chu-caen.fr

Sophie RAMAKAERS (MD) ramakers-s@chu-caen.fr.

Intensive care Unit, University Hospital, (Rue Montalemberg), Clermont-

Ferrand, (63000), France : Norddine AIT-BEN-SAID: naitbensaid@chu-

clermontferrand.fr

Russell CHABANNE: rchabanne@chu-clermontferrand.fr

Sylvia COLOMB: scolomb@chu-clermontferrand.fr

Thierry GILLART: tgillart@chu-clermontferrand.fr

Dominique GUELON: dguelon@chu-clermontferrand.fr.

Intensive care Unit, University Hospital AP-HP, (Marechal de Lattre), Créteil,

(94210), France): Fabrice COOK: fabrice.cook@hmn.aphp.fr

Benoit PLAUD: benoit.plaud@hmn.aphp.fr

Coralie VIGNE: coralie.vigne@hmn.aphp.fr.

Intensive care Unit, University Hospital, (Rue de Lattre de Tassigny), Dijon, (77208), France:

Marc FREYSZ: marc.freysz@chu-dijon.fr

Abdelouaid NADJl: Abdelouaid.NADJI@chu-dijon.fr.

Intensive care Unit, Hôpital Européen Georges Pompidou AP-HP, (Rue

Leblanc), Paris, (75908), France:

Didier JOURNOIS: d.journois@invivo.edu

Alix LAGRANGE: alix.lagrange@gmail.com

Romain PIRRACCHIO: romainpirracchio@yahoo.fr

Frank THOMAS: fthomas@live.fr.

Intensive care Unit, Hospices Civiles de Lyon, (Place Arsonval), Lyon (69003),

France:

Bernard ALLAOUCHICHE: bernard.allaouchiche@chu-lyon.fr

Etienne HAUTIN: hautin.etienne@gmail.com.

Intensive care Unit, University Hospital of Saint Eloi (Avenue Augustin),

Montpellier, (34295), France: Stéphane FOURNIER: s-fournier@chu-montpellier.

$\mathrm{fr}$

Pierre François PERRIGAULT: pf-perrigault@chu-montpellier.fr

Intensive care Unit, University Hospital of Lapeyronie, (Rue Doeyn Giraud), Montpellier, (34090), France:

Priscilla AMARU: p-amaru@chu-montpellier.fr

Xavier CAPDEVILLA: x-capdevila@chu-montpellier.fr.

Intensive care Unit, Hotel Dieu, (Place Ricordeau), Nantes (44093), France:

Karim ASEHNOUNE: karim.asehnoune@chu-nantes.fr

Philippe CHAMPIN: philippe.champin@chu-nantes.fr

Dominique DEMEURE DIT LATTE: dominique.demeureditlatte@chu-nantes.fr

Olivier LOUTREL: Olivier.LOUTREL@chu-nantes.fr

Edouard NAUX: edouard.naux@chu-nantes.fr

Pierre Joachim MAHE: pierrejoachim.mahe@chu-nantes.fr

Antoine ROQUILLY: antoine.roquilly@chu-nantes.fr

Intensive care Unit, University Hospital, (Rue Debre), Nîmes (30029), France:

Pascal JEANNĖS: pascal.jeannes@chu-nimes.fr

Jean- Yves LEFRANT: jean.yves.lefrant@chu-nimes.fr

Guillaume LOUART: guillaume.louart@chu-nimes.fr.

Intensive care Unit, University Hospital, (Rue de la Milétrie), Poitiers (86021), France:

Claire DAHYOT-FIZELIER: c.dahyot-fizelier@chu-poitiers.fr

Oliver MIMOZ: o.mimoz@chu-poitiers.fr.

Intensive care Unit, University Hospital, (Rue Le Guilloux), Rennes, (35000),

France:

Jean-Paul BLEICHNER: jeanpaul.bleichner@chu-rennes.fr

Sonia ISSLAME: sonia.isslame@chu-rennes.fr

Yoan LAUNEY: yoan.launey@chu-rennes.fr

Pascale LE MAGUET: Pascale.leMAGUET@chu-rennes.fr
Yannick MALLEDANT: yannick.malledant@chu-rennes.fr

Nicolas NESSELER: nicolas.nesseler@chu-rennes.fr

Philippe SEGUIN: philippe.seguin@chu-rennes.fr

Deborah TARTIERE: deborah.tartiere@chu-rennes.fr.

Intensive care Unit, University Hospital, (Place de l'hopital), Strasbourg

(67091), France: Bartholomeus CALON: bartholomeus.calon@chru-strasbourg. $\mathrm{fr}$

Thierry POTTECHER: thierry.pottecher@chru-strasbourg.fr.

Intensive care Unit, University Hospital, (Rue Jean Poulhes) Toulouse, (50032),

France:

Olivier FOURCADE: fourcade.o@chu-toulouse.fr

Thomas GEERRAERTS: geeraerts.thomas@gmail.com

Sandrine SACRISTA: sacrista.s@chu-toulouse.fr.

Intensive Care Unit of Saint Louis, Assistance Publique-Hôpitaux de Paris,

(Avenue Vellefaux), and for the FAMIREA group, Paris (75010), France:

Elie AZOULAY: elie.azoulay@sls.ap-hop-paris.fr

Cellule de Biostatistique - \& EA 4275 - UFR de Pharmacie University, (Rue

Veille), Nantes (44000), France:

Véronique SEBILLE: veronique.sebille@univ-nantes.fr

Funding

This work is supported by a grant from the Societe Française d'Anesthesie Reanimation (SFAR)

\section{Author details}

${ }^{1}$ Centre Hospitalier Universitaire de Nantes, Service d'anesthésie réanimation chirurgicale, Hôtel Dieu-HME, Nantes, France. ${ }^{2}$ Intensive care Unit, Hotel Dieu, (Place Ricordeau), Nantes (44093), France. ${ }^{3}$ Biostatistics Unit. EA 4275, Pharmacy University of Nantes, Nantes F-44000 France. ${ }^{4}$ The Corti-TC trial group.

\section{Authors' contributions}

KA, AR: preparation of the initial drafts of the manuscript and preparation of the final version. The corti-TC trial group: review of the initial drafts of the manuscript. VS: planned the statistical analysis and revised the manuscript. $K A, A R$, VS: designed the study, reviewed the initial drafts of the manuscript. All authors approved the final version of the manuscript.

\section{Competing interests}

The authors declare that they have no competing interests.

Received: 26 September 2011 Accepted: 14 October 2011

Published: 14 October 2011

\section{References}

1. Pelosi P, Ferguson ND, Frutos-Vivar F, Anzueto A, Putensen C, Raymondos K, Apezteguía C, Desmery P, Hurtado J, Abroug F, Elizalde J, Tomicic V, Cakar N, González M, Arabi Y, Moreno R, Esteban A, for the Ventila Study Group: Management and outcome of mechanically ventilated neurologic patients. Critical Care Medicine 2011, 39:1482-1492.

2. Seguin $P$, Tanguy ML, Laviolle $B$, Tirel O, MalleDant Y: Effect of oropharyngeal decontamination by povidone-iodine on ventilatorassociated pneumonia in patients with head trauma. Critical Care Medicine 2006, 34:1514-1519.

3. Lepelletier D, Roquilly A, Demeure dit latte D, Mahe PJ, Loutrel O, Champin P, Corvec S, Naux E, Pinaud M, Lejus C, Asehnoune K: Retrospective analysis of the risk factors and pathogens associated with early-onset ventilator-associated pneumonia in surgical-ICU head-trauma patients. J Neurosurg Anesthesiol 2010, 22:32-37.

4. Bronchard R, Albaladejo P, Brezac G, Geffroy A, Seince PF, Morris W, Branger $C$, Marty J: Early onset pneumonia: risk factors and consequences in head trauma patients. Anesthesiology 2004, 100:234-239.

5. Osborn TM, Tracy JK, Dunne JR, Pasquale M, Napolitano LM: Epidemiology of sepsis in patients with traumatic injury. Critical Care Medicine 2004, 32:2234-2240.

6. Rincón-Ferrari MD, Flores-Cordero JM, Leal-Noval SR, Murillo-Cabezas F, Cayuelas A, Muñoz-Sánchez MA, Sánchez-Olmedo Jl: Impact of ventilatorassociated pneumonia in patients with severe head injury. The Journal of Trauma: Injury, Infection, and Critical Care 2004, 57:1234-1240.

7. Czaja AS, Rivara FP, Wang J, Koepsell T, Nathens AB, Jurkovich GJ, Mackenzie E: Late outcomes of trauma patients with infections during index hospitalization. J Trauma 2009, 67:805-814. 
8. Safdar N, Dezfulian C, Collard HR, Saint S: Clinical and economic consequences of ventilator-associated pneumonia: a systematic review. Critical Care Medicine 2005, 33:2184-2193.

9. Hoen S, Asehnoune K, Brailly-Tabard S, Mazoit JX, Benhamou D, Moine P, Edouard A: Cortisol response to corticotropin stimulation in trauma patients: influence of hemorrhagic shock. Anesthesiology 2002, 97:807-813.

10. Roquilly A, Mahe PJ, Seguin P, Guitton C, Floch H, Tellier AC, Merson L, Renard B, Malledant Y, Lfet L, Sebille V, Volteau C, Masson D, Nguyen JM, Lejus $C$, Asehnoune $K$ : Hydrocortisone therapy for patients with multiple trauma: the randomized controlled HYPOLYTE study. JAMA 2011, 305:1201-1209.

11. Cohan P, Wang C, Mcarthur DL, Cook SW, Dusick JR, Armin B, Swerdloff R, Vespa P, Muizelaar JP, Cryer JG, Christenson PD, Kelly DF: Acute secondary adrenal insufficiency after traumatic brain injury: A prospective study. Critical Care Medicine 2005, 33:2358-2366.

12. Woiciechowsky C, Schöning B, Lanksch WR, Volk HD, Döcke WD: Mechanisms of brain-mediated systemic anti-inflammatory syndrome causing immunodepression. J Mol Med 1999, 77:769-780.

13. Annane D, Sébille V, Charpentier C, Bollaert PE, François B, Korach JM, Capellier G, Cohen Y, Azoulay E, Toché G, Chaumet-Riffaud P, Bellissant E: Effect of treatment with low doses of hydrocortisone and fludrocortisone on mortality in patients with septic shock. JAMA 2002, 288:862-871.

14. Bederson JB, Connolly ES, Batjer HH, Dacey RG, Dion JE, Diringer MN, Duldner JE, Harbaugh RE, Patel AB, Rosenwasser RH, American Heart Association: Guidelines for the management of aneurysmal subarachnoid hemorrhage: a statement for healthcare professionals from a special writing group of the Stroke Council, American Heart Association. Stroke 2009, 40:994-1025.

15. Sartorius D, Le Manach Y, David JS, Rancurel E, Smail N, Thicoïpé M, Wiel E, Ricard-Hibon A, Berthier F, Geugniaud PY, Riou B: Mechanism, Glasgow Coma Scale, Age, and Arterial Pressure (MGAP): A new simple prehospital triage score to predict mortality in trauma patients. Critical Care Medicine 2010, 38:831-837.

16. Fine J, Gray R: A proportional hazards model for the subdistribution of a competing risk. J Am Statist Assoc 1999, 94:496-509.

17. Keh D, Boehnke T, Weber-Cartens S, Schulz C, Ahlers O, Bercker S, Holk HD, Doecke WD, Falke KJ, Gerlach H: Immunologic and hemodynamic effects of "low-dose" hydrocortisone in septic shock: a double-blind, randomized, placebo-controlled, crossover study. American Journal of Respiratory and Critical Care Medicine 2003, 167:512-520.

18. Confalonieri M, Urbino R, Potena A, Piatella M, Parigi P, Pussio G, Porta RD, Giogio C, Blasi F, Umberger R, Meduri GU: Hydrocortisone Infusion for Severe Community-acquired Pneumonia: A Preliminary Randomized Study. American Journal of Respiratory and Critical Care Medicine 2004, 171:242-248.

19. Marik PE: Critical IIIness-Related Corticosteroid Insufficiency. Chest 2009, 135:181-193

20. Klompas M: The paradox of ventilator-associated pneumonia prevention measures. Crit Care 2009, 13:315.

21. Bandiera GW, Hillers TK, White F: Evaluating programs to prevent unintentional trauma in Canada: challenges and directions. The Journal of Trauma: Injury, Infection, and Critical Care 1999, 47:932-936.

22. Snijders D, Daniels JMA, De Graaff CS, Der Werf Van TS, Boersma WG Efficacy of Corticosteroids in Community-acquired Pneumonia: A Randomized Double-Blinded Clinical Trial. American Journal of Respiratory and Critical Care Medicine 2010, 181:975-982.

23. American Thoracic Society, Infectious Diseases Society of America: Guidelines for the management of adults with hospital-acquired, ventilator-associated, and healthcare-associated pneumonia. American Journal of Respiratory and Critical Care Medicine 2005, 171:388-416.

24. Brain Trauma Foundation, American Association of Neurological Surgeons, Congress of Neurological Surgeons: Guidelines for the management of severe traumatic brain injury. J Neurotrauma 2007, 24(Suppl 1):S1-106.

25. Terragni PP, Antonelli M, Fumagalli R, Faggiano C, Berardino M, Pallavicini FB, Miletto A, Mangione S, Sinardi AU, Pastorelli M, Vivaldi N, Pasetto A, Rocca GD, Urbino R, Filippini C, Pagano E, Evangelista A, Ciccone G, Mascia L, Ranieria M: Early vs late tracheotomy for prevention of pneumonia in mechanically ventilated adult ICU patients: a randomized controlled trial. JAMA 2010, 303:1483-1489.
26. Den Berghe Van G, Wilmer A, Hermans G, Meersseman W, Wouters PJ Milants I, Van Wijngaerden E, Bobbaers H, Bouillon R: Intensive insulin therapy in the medical ICU. N Engl J Med 2006, 354:449-461.

27. NICE-SUGAR Study Investigators, Finfer $S$, Chittock DR, Su SY-S, Blair D, Foster D, Dhingra V, Bellomo R, Cook D, Dodek P, Henderson WR, Hebert PC, Heritier S, Heyland DH, McArthur C, McDonald E, Mitchell I, Myburgh JA, Norton R, Potter J, Robinson BG, Ronco JJ: Intensive versus conventional glucose control in critically ill patients. N Engl J Med 2009, 360:1283-1297.

28. Annane D, Bellissant E, Bollaert PE, Briegel J, Confalonieri M, De Gaudio R, Keh D, Kupfer Y, Oppert M, Meduri GU: Corticosteroids in the Treatment of Severe Sepsis and Septic Shock in Adults: A Systematic Review. JAMA 2009, 301:2362-2375.

29. Marik PE, Pastores SM, Annane D, Umberto Meduri G, Sprung CL, Arlt W Keh D, Briegel J, Beishuizen A, Dimopoulou I, Tsagarakis S, Singer M, Chrousos GP, Zaloga G, Bokhari F, Vogeser M: Recommendations for the diagnosis and management of corticosteroid insufficiency in critically ill adult patients: Consensus statements from an international task force by the American College of Critical Care Medicine. Critical Care Medicine 2008, 36:1937-1949.

30. Annane D, Maxime V, Ibrahim F, Alvarez JC, Abe E, Boudou P: Diagnosis of Adrenal Insufficiency in Severe Sepsis and Septic Shock. American Journal of Respiratory and Critical Care Medicine 2006, 174:1319-1326.

31. Reynolds SF, Heffner J: Airway management of the critically ill patient: rapid-sequence intubation. Chest 2005, 127:1397-1412.

32. Schenarts $\mathrm{CL}$, Burton JH, Riker RR: Adrenocortical dysfunction following etomidate induction in emergency department patients. Acad Emerg Med 2001, 8:1-7.

33. Malerba G, Romano-Girard F, Cravoisy AL, Dousset B, Nace L, Levy B, Bollaert PE: Risk factors of relative adrenocortical deficiency in intensive care patients needing mechanical ventilation. Intensive Care Med 2005, 31:388-392.

34. Albert SG, Ariyan $\mathrm{S}$, Rather $\mathrm{A}$ : The effect of etomidate on adrenal function in critical illness: a systematic review. Intensive Care Med 2011, 37:901-910.

doi:10.1186/1745-6215-12-228

Cite this article as: Asehnoune et al:: Corticotherapy for traumatic braininjured Patients - The Corti-TC trial: study protocol for a randomized controlled trial. Trials 2011 12:228.

\section{Submit your next manuscript to BioMed Central and take full advantage of:}

- Convenient online submission

- Thorough peer review

- No space constraints or color figure charges

- Immediate publication on acceptance

- Inclusion in PubMed, CAS, Scopus and Google Scholar

- Research which is freely available for redistribution

Submit your manuscript at www.biomedcentral.com/submit
Ciomed Central 